progression-free survival time was 120 months for grade II and 18 months for grade III ependymomas. (Ernestus R-I, Schroder R, Stutzer H, Klug N. Prognostic relevance of localization and grading in intracranial ependymomas of childhood. Child's Nerv Syst Sept 1996;12:522-526). (Respond: Dr Ralf-Ingo Ernestus, N Klug Klinik fur Neurochirurgie der Universitat zu Koln, JosephStelzmann-Strasse 9, D-50924 Koln, Germany).

COMMENT. As might be expected, the progression-free survival time is longer for the grade II ependymomas than the anaplastic grade III tumors, despite incomplete operative removal of the less malignant type.

Prognosis of cerebral oligodendrogliomas is studied in 15 children operated on at the Hopital Pierre Wertheimer, Lyon, France. Two groups were recognized: 1). Seven presenting with epilepsy had benign tumors and all survived at 72-month follow-up; 2). Eight presenting with intracranial hypertension had malignant anaplastic tumors, and 6 died within 17 months despite postoperative radiotherapy and chemotherapy. Clinical presentation and histology were correlated with survival time. (Rizk T, Mottolese C, Bouffet E et al. Cerebral oligodendrogliomas in children: an analysis of 15 cases. Child's Nerv Syst Sept 1996;12:527-529).

\title{
METABOLIC AND ENDOCRINE DISORDERS
}

\section{MATERNAL DIABETES AND INFANT INTELLIGENCE}

The intellectual development of 33 children born to 33 diabetic Japanese mothers (ODM) was compared to that of 34 control offspring of non-diabetics delivered at Kurume University Hospital, Fukuoka, Japan, between 1987 and 1989. Intelligence scores on the Tanaka-Binet test were significantly lower in the ODMs at 3 years of age than in controls. Maternal age and infant IQ were inversely correlated in ODMs but not in controls. (Yamashita Y, Kawano Y, Kuriya $\mathrm{N}$ et al. Intellectual development of offspring of diabetic mothers. Acta Paediatr Oct 1996;85:1192-1196). (Respond: Dr Y Yamashita, Department of Paediatrics and Child Health, Kurume University School of Medicine, 67 Asahi-machi Kurume-city, Fukuoka 830, Japan).

COMMENT. Infants of diabetic mothers may be at risk for impaired intellectual development, and especially infants born to older mothers. The difference in IQ between offspring of diabetics and non-diabetics was not associated with maternal toxemia or postnatal hyperbilirubinemia or hypoglycemia. A longer period of follow-up was considered important in determining the final cognitive outcome of these children.

Severe hypoglycemia and cognitive impairment in diabetes is reviewed and the link is considered not proven in a report from the Department of Psychology, University of Edinburgh, and Department of Diabetes, Royal Infirmary of Edinburgh. (Deary IJ, Frier BM. BMI 28 Sept 1996;313:767-768). Among young adults with insulin dependent diabetes, recurrent episodes of severe hypoglycemia over a 5 to 15 year period have either a mild or negligible effect on cerebral function, except for a few subjects who are unusually vulnerable and suffer permanent brain damage. While strict glycemic control delays onset of retinopathy, nephropathy, and neuropathy, it is associated with a threefold increase in severe hypoglycemia. 